\title{
STUDY OF AUTONOMIC ACTIVITIES IN PRIMARY OPEN ANGLE GLAUCOMA
}

\author{
Mohammad Monis Khan'1, Subarna Ghosh', Chandana Bera ${ }^{3}$ \\ ${ }^{1}$ Assistant Professor, Department of Physiology, Gold Field Institute of Medical Sciences \& Research. \\ ${ }^{2}$ Tutor (Demonstrator), Department of Physiology, Gold Field Institute of Medical Sciences \& Research. \\ ${ }^{3}$ Tutor (Demonstrator), Department of Physiology, Gold Field Institute of Medical Sciences \& Research.
}

\section{ABSTRACT}

In the late nineteenth century authors established the concept of involvement of Automatic Nervous System (ANS), including both sympathetic and parasympathetic division in the various systemic disorders. ANS help to maintain the ocular blood flow at a suitable level during sudden increments in blood pressure and also influence the steady state level of Intraocular Pressure (IOP) by altering the rate of aqueous production in eye. Glaucoma is characterized by a progressive optic neuropathy resulting in irreversible damage to the optic nerve and visual field leading to blindness. Glaucoma has also been associated with ANS, which affects aqueous dynamics and therefore IOP. The diagnosis of autonomic neuropathy may be based on clinical symptoms on nerve biopsies or on attenuation of reflexes. In India the most common form of glaucoma is the Primary Open-Angle Glaucoma (POAG). The present study is undertaken with similar objectives to provide a further insight to this common and preventable disorder.

\section{AIMS}

To compare the autonomic functions of POAG and normal subjects (Control).

\section{MATERIALS AND METHODS}

The various autonomic function tests including Resting Heart Rate, Postural Pressor Response, Valsalva Ratio, Cold Pressor Response, Corrected QT Interval, T-Wave Amplitude of EKG were performed in 30 normal healthy subjects (Control) and 30 Primary Open Angle Glaucoma (POAG) patients in Gold Field Hospital, Faridabad.

\section{STATISTICAL ANALYSIS}

Intergroup mean differences were tested for significance by Stusent standard ' $\mathrm{t}$ ' tests by using SPSS software version- 17.0.

\section{RESULTS}

There is significant $(\mathrm{p}<0.05)$ decrease in both sympathetic and parasympathetic activity in POAG in comparison to normal subject.

\section{CONCLUSION}

POAG showed decrease in both sympathetic and parasympathetic activity.

\section{KEYWORDS}

Glaucoma, Parasympathetic Effect on Eye, Autonomic Activity and Glaucoma.

HOW TO CITE THIS ARTICLE: Khan MM, Ghosh S, Bera C. "Study of autonomic activities in primary open angle glaucoma.” Journal of Evolution of Medical and Dental Sciences 2015; Vol. 4, Issue 103, December 24; Page: 16865-16870,

DOI: $10.14260 /$ jemds $/ 2015 / 2536$

\section{INTRODUCTION}

In the late nineteenth century authors established the concept of involvement of ANS in the various systemic disorder viz. diabetes, cerebral pathology etc. ${ }^{1}$ ANS is the part of the peripheral nervous system that control visceral functions, consists of Sympathetic and Parasympathetic divisions that respectively have thoracolumbar "Out flow" (T-1 to L-2) and craniosacral "Out flow," i.e. cranial nerves (CN-III, VII, IX, X) and sacral (S-2 to 4) portion spinal cord. ${ }^{2}$ The ANS requires a sequential 2 neuronal efferent pathway, the preganglionic neuron will begin at the "outflow" and will synapse at the postganglionic neuron, which in turn synapses at the target organ. ${ }^{3}$ Epinephrine and norepinephrine are the neurotransmitters of sympathetic division act on receptors $\beta 1$, $\beta 2, \alpha 1, \alpha 2$.

Financial or Other, Competing Interest: None.

Submission 04-12-2015, Peer Review 05-12-2015

Acceptance 18-12-2015, Published 24-12-2015.

Corresponding Author:

Dr. Mohammad Monis Khan,

211 - B, LIG Flats Pocket 12,

Jasola Vihar,

New Delhi-110025.

E-mail:gbubai@rocketmail.com

DOI:10.14260/jemds/2015/2536
Acetylcholine is the neurotransmitter of parasympathetic division which acts on muscarinic, nicotinic receptors. ${ }^{4}$ Recently, a third subsystem of neurons came into view that have been named 'noradrenergic' and 'norcholinergic' neurons because they use nitric oxide as a neurotransmitter. ${ }^{5}$

\section{Ocular Circulation}

Sympathetic nerves derived from the superior cervical ganglion, innervate the central retinal artery upto the lamina cribrosa and all uveal beds. ${ }^{6}$ Scientists demonstrated that many sympathetic nerves contain neuropeptide-Y, whose distribution resembles adrenergic innervation. ${ }^{7}$ Ocular parasympathetic nerves consist of oculomotor and facial nerve control ocular blood flow; the facial nerve innervates mainly choroidal vessels and transmitter is probably Vasoactive Intestinal Peptide (VIP). ${ }^{8}$ The vascular nerves with VIP-like immunoreactivity have also been found in the human eye. Sensory nerves of the trigeminal origin containing the Substance P (SP) and Calcitonin Gene Relating Peptide (CGRP) are also associated with uveal blood vessels, mainly in the ciliary body and to some extant in the choroid. ${ }^{9}$ Scientists also demonstrated that the sympathetic stimulation reduces blood flow through all parts of uveal tissues via $\alpha$ receptor, whereas retinal blood flow is unaffected. ${ }^{10}$ One important physiological 
role of the sympathetic nerves is to help to maintain the ocular blood flow at a suitable level during sudden increments in blood pressure.

\section{Aqueous Humor}

The non-pigmented epithelium of ciliary processes actively secretes aqueous humor into the posterior chamber, which in turn generates the IOP. Parasympathetic fibers originate in the Edinger Westphal nucleus of the IIIrd cranial nerve in the orbit and synapses in the ciliary ganglion within the short ciliary nerves and in the ciliary body. ${ }^{11}$ Sympathetic fibers synapse in the superior cervical ganglion and distributed to the muscles and blood vessel of the ciliary body. Clinical observation and experimental data of studies suggest that neural and humoral pathways influence the steady state level of IOP by altering the rate of aqueous production. ${ }^{12}$

Ocular Hypertention is IOP higher than normal without optic nerve damage or visual field loss. Correct consensus in ophthalmology defines normal IOP is $10 \mathrm{mmHg}$ to $21 \mathrm{mmHg}$. Elevated IOP is the most important risk factor for glaucoma.

Glaucoma is characterized by a progressive optic neuropathy result in irreversible damage to the optic nerve, head and visual field leading to blindness, affecting some 67 million people worldwide. ${ }^{13}$ It is of 2 types- Primary and Secondary. The former one again are of 2 types- Open Angle and Close Angle.

Primary Open Angle Glaucoma (POAG) is a chronic, progressive, multifactorial, bilateral optic neuropathy which develops slowly and quietly over the age of 40 years and insidiously over many years with a characteristics triad of symptoms- raised tension, typical field defects and cupping of the disc- until in the "absolute" stage the eye become intensely hard, all vision is lost and disc develops a deep atrophic cup. POAG occurs equally in both sexes with increased resistance to aqueous out flow in drainage channel. ${ }^{14}$ In India POAG is one of the leading cause of blindness that accounts for $1.6 \%$ to $4 \%$ of people. ${ }^{15}$ POAG is the most common form of glaucoma and one of the major causes of irreversible adult blindness throughout the world. ${ }^{16}$ Approximately, $1-2 \%$ of the population over 40 years old and $10 \%$ of people aged over 70 years are affected. ${ }^{15}$

Primary Close Angle Glaucoma (PCAG) occurs usually in women, in the fifth or sixth decade. The affected eye develops obstruction of aqueous out flow by partial or complete closure of angle by peripheral iris with lens-iris diaphragm far forward and its angle narrow. The chronic phase is untreated with or without the occurrence of intermittent sub-acute attacks, gradually passes into the final phase of absolute glaucoma, wherein the eye is completely blind. ${ }^{16}$

\section{Secondary Glaucoma}

Hypertensive uveitis, thrombosis of the central vein of retina, dislocation of the lens, intraocular tumor and venous obstruction are the causes for the development of secondary glaucoma. In the initial stage of disease the IOP may not be raised permanently but shows exaggerated diurnal variation. ${ }^{17}$ Due to constant pressure on the ciliary muscles and its nerve supply, reading and close work often present with increasing difficulties with mild headache and eye ache. Early glaucomatous changes include asymmetry of the cup, visible fenestration, vertically oval large cupping, splinter haemorrages and pallor area with atrophy of retinal nerve fiber layer. Advanced glaucomatous changes included thinning of neural retinal rim bayonetting blood vessels with marked cupping and lamina cribrosa. Visual field defect corresponds to the changes at the optic nerve and gradually spreads centrally as well as peripherally. Eventually only a small island of central vision and temporal islands are left. ${ }^{18}$
Glaucoma has also been associated with autonomic nervous system affects aqueous dynamics and therefore IOP. The diagnosis of autonomic neuropathy may be based on clinical symptoms on nerve biopsies or on attenuation of reflexes.

\section{Selection Criteria}

\section{Exclusion Criteria}

a. Subject suffering from hypertension/hypotension.

b. Subject having medical illness associated with autonomic neuropathy.

c. Subject having pyrexia.

d. Subjects on long-term medication or under treatment.

e. Heavy smoker and alcoholic.

\section{Inclusion Criteria}

Subjects will be diagnosed case of POAG with open anterior angle by gonioscopy and intra ocular pressure $25.2 \pm 5.08 \mathrm{mmHg}(18.9-34.4 \mathrm{mmHg})$ and field defects typical of POAG.

\section{Selection of Normal Subjects}

Normal subjects were selected by the random sampling. Each subject was given a thorough physical examination and history was taken to exclude any medical illness associated autonomic neuropathy. The subjects chosen were nonglaucomatous, nonalcoholic, nondiabetic and normostensive with IOP $16.9 \pm 2.79 \mathrm{mmHg}(13.4-21.9 \mathrm{mmHg})$.

\section{METHODOLOGY}

\section{Anthropometry}

All the subjects studied were males/females. They belonged to the age group of $45 \pm 15$ years (i.e. 30 to 60 years age group) and their weight ranged from $130-175 \mathrm{lb}$ and their body surface area $1.5-1.9$ square meters $(1.67 \pm 0.04$ square meters).

\section{Parameters Recorded}

Height, Weight, Body Surface Area (BSA).

\section{Test to assess parasympathetic activity}

1. Resting Heart Rate- Using EKG.

2. Standing to Lying (S/L) Ratio (Postural Pressor Response).

3. Valsalva Ratio.

\section{Test to assess sympathetic activity}

1. Cold Pressor Response (CPR).

2. Corrected QT Interval $\left(\mathrm{QT}_{\mathrm{c}}\right)$.

3. T-Wave Amplitude of EKG.

\section{Preparation of the Subjects}

The nature of the tests were explained to the subjects beforehand. History taking and the medical examination was carried out for half an hour during, which the subject gets acclimatized to the environment of the examination cum investigation room. All the tests were performed at the same time of the day (2-4 PM) in all subjects. The tests were carried out at a comfortable environmental temperature $\left(27 \pm 1^{\circ} \mathrm{C}\right.$.) in the laboratory.

\section{PROCEDURE}

\section{Height}

Height was measured in $\mathrm{cm}$ by using the anthropometric scale, the range of the scale used as $140-190 \mathrm{cms}$ and its sensitivity (Least count) was $0.5 \mathrm{~cm}$.

\section{Weight}

Weight was measured (In lbs) using the Avery-n machine, the capacity of which was using was $120 \mathrm{lbs}$ and sensitivity was $0.05 \mathrm{lbs}$ 


\section{Body Surface Area}

Body surface area was calculated in square meter (Sq. m) from the height and weight of the subject, using McKesson's nomogram.

\section{To assess parasympathetic activity \\ Resting Heart Rate}

This was calculated from the EKG recording. The EKG recording was done in the conventional way using the standard limb lead-II with frequency range chosen was from $0.1 \mathrm{~Hz}$ to $70 \mathrm{~Hz}$, sensitivity was set at $1 \mathrm{mv} / \mathrm{cm}$. The longest R-R interval in lead II was measured with the help of a ruler and the heart rate calculated.

\begin{tabular}{l}
$\begin{array}{l}\text { Heart rate } \\
\text { (Beats/min) }\end{array} \quad=\frac{1}{\text { Max R-R interval (in sec) }} \times 60$ \\
\hline
\end{tabular}

Standing to Lying (S/L) Ratio (Postural Pressor Response) The procedure of the test was explained in simple terms to the subject. He was given a few trials to make him familiar with the test. Each subject was asked to stand quietly and then lies down without help while a continuous EKG was made from 20 beats before to 60 beats after lying down. The point at which the subject started to lie down was marked the test was performed three times. The data was analyzed as per the method of Ewing. ${ }^{19}$ The individual R-R intervals were measured with a ruler from the EKG and the results are expressed as a ratio of the longest R-R interval during the five beats before lying down to the shortest $\mathrm{R}-\mathrm{R}$ interval during the ten beats after lying down (i.e. standing to lying $\mathrm{S} / \mathrm{L}$ ratio).

Sil. RATtO - $\frac{\text { Longest RR interval during the fiwe beats before lying down }}{\text { Shortest RR interval during the teo beats after lying down }}$

The maximum ratio of the three trails was taken for the autonomic activity.

\section{Valsalva Ratio}

Each subject performed valsalva maneuver for $15 \mathrm{sec}$ by blowing against a mouth piece-attached to aneroid manometer and maintain a pressure of $40 \mathrm{mmHg}$ for $15 \mathrm{sec}$. Three trials were performed at an interval of $5 \mathrm{~min}$. Continuous EKG was recorded 1 min before the maneuver (i.e. resting period) during the maneuver and strain period of 15 sec and $60 \mathrm{sec}$ subsequent to strain period. Valsalva ratio was taken as ratio of longest R-R interval after the strain to that of the shortest R-R interval during the strain.

Valsalva Ratio $=\frac{\text { Max R-R interval after the strain }}{\text { Shortest } R-R \text { interval during the strain }}$

\section{Test to assess sympathetic activity}

\section{Corrected QT Interval}

Since the QT interval duration various with the heart rate the corrected QT interval (QTc), which standardises the QT interval for rate from the EKG, was calculated using the Bazett formula. ${ }^{20}$ $\mathrm{QTC}=\mathrm{QT} / \mathrm{RR}$ interval $($ Bazett $) \cdot{ }^{20}$

\section{T-Wave Amplitude}

The T-wave amplitude was measured using a ruler in $\mathrm{mm}$ and was converted into the millivolts as the EKG sensitivity was set at $1 \mathrm{mV} / \mathrm{cm}$, i.e. $\mathrm{T}$ wave Height of $1 \mathrm{~mm}=0.1 \mathrm{mV}$.

\section{Cold Pressor Response (CPR)}

The test was done as one of the last tests in the experimental protocol because of slight unpleasantness of the test. It was done as per the method of Le Blanc et al. ${ }^{21}$ After resting for about half an hour comfortably the subject while sitting was exposed to the cold hand test.

The nature of the test was explained to the subjects and they were told that the test was a bit painful procedure, but at the same time they were also reassured that the test would not do any harm to the subject.

With the subject sitting comfortably blood pressure measurements were made at few minute intervals and the test was started when consistent blood pressure readings were obtained. The subject was then asked to immerse his hand in a jug of water with temperature maintained at $7-10^{\circ}$ throughout the test. Blood pressure measurements were made from the other arm at $30 \mathrm{sec}$ intervals for a period of two minutes. Thus five $\mathrm{BP}$ readings were obtained in all, i.e. $1^{\text {st }}$ reading is taken before the start of test (i.e. resting BP) and subsequently four readings during the test at $30 \mathrm{sec}$ intervals. After two minutes the subject was allowed to take off his hand from the jug. Throughout the test, the subject was reassured again and again. The maximum increase in the systolic and the diastolic blood pressure was determined and the results recorded. In any condition where there is deficient sympathetic outflow, the cold pressor test will be expected to show a smaller rise in blood pressure.

\section{STATISTICAL ANALYSIS}

For each variable groups of the autonomic function test performed in the study of glaucomatous patients mean and standard deviation of the results were calculated according to the accepted statistical methods. Intergroup mean differences were tested for significance by Student standard ' $t$ ' tests by using SPSS software version- 17.0.

\section{RESULT}

- Table 4.1 and Fig. 1 shows that there is no significant $(p=0.510)$ difference in mean age of the two groups of subjects, i.e. Control and POAG.

- Tables 4.2, 4.3 and Fig. 2, 3 shows that there is no significant (respectively, $\mathrm{p}=0.176,0.23600$ ) difference in anthropometric parameters among the two groups in terms of height, weight and body surface area.

- Table 4.4 and Fig 4 shows that the mean T-wave amplitude of lead II of EKG (X) is significantly ( $\mathrm{p}=0.00)$ less in POAG group as compared to the control group.

- Table 4.5, 4.6 and Fig. 5, 6 shows respectively that the mean systolic and diastolic CPR is significantly less $(p=0.00,0.00)$ in POAG group as compared to the control group.

- $\quad$ Table 4.7 and Fig 7 shows that the mean corrected QTC interval $\left(\mathrm{QT}_{\mathrm{C}}\right)$ of lead II of EKG is significantly $(\mathrm{p}=0.00)$ less in POAG group of subjects when compared with control group of subjects.

- Table 4.8 and Fig. 8 shows that there is no significant $(p=0.112)$ difference in mean resting heart rate of the subjects of the two groups.

- As shown in Table 4.9 and Fig 9, the mean standing to lying ratio is significantly $(\mathrm{p}=0.0510)$ less in POAG groups as compared to the control group.

- As shown in Table 4.10 and Fig 10, the mean Valsalva ratio is highly significantly $(\mathrm{p}=0.0001)$ less in POAG groups as compared to the control group.

\section{DISCUSSION}

The result of present study showed that both the parameters used for sympathetic as well as parasympathetic activities 
were found to be statistically highly significant except in the case of resting heart rate. No changes were observed in normal subjects. The conclusion of the present study was compared with those of previous studies of the same nature and results were drawn. The present study shows that in POAG cases both the systolic CPR $(17.27 \pm 3.463 \mathrm{mmHg})$ and diastolic CPR $(14.27 \pm 4.258 \mathrm{mmHg})$ significantly decrease. Kumar R. and Ahuja V. M. observed decrease in both systolic CPR in 36 patients out of 50 patients (73\%) and diastolic CPR in 43 patients out of $50(86 \%)$ of the POAG subjects when compared with normal control group. ${ }^{22}$ Le Blance et al. (1967) demonstrated that under any condition, which causes stress of either physical or psychological origin, there is activation of sympathetic nervous system noted.21 Godden J.0. demonstrated that the different never fibers for this response are the pain fibers, which are stimulated by placing the hand in cold water and these are the sympathetic fibers. ${ }^{23}$

The response of $15 \mathrm{mmHg}$ increase in blood pressure is considered as normal response to cold pressor test in normal individuals. Gherghel et al. performed a modified cold pressor response test in 24 patients with POAG and 22 controls and found a differing blood pressure and ocular blood flow response in patients with POAG suggestive of systemic autonomic failure and ocular vascular dysregulation. ${ }^{24} \mathrm{~T}$-wave amplitude confirms the decrease of sympathetic activity. Table 4.5 shows $(0.161 \pm 0.1535 \mathrm{mV})$ in POAG cases. According to Furedy and Haselgrave T- wave amplitude is a measure of the sympathetic activity of the heart. ${ }^{25}$ In the present study, relative tachycardia along with decrease in T-wave amplitude is seen when compared with normal group of subjects.

This might be explained on the basis that T-wave amplitude is a function of parasympathetic activity. Hence, the change in the $\mathrm{T}$-wave amplitude in the present study may be related to alteration of sympathetic function. The result of a study done by Kumar R and Ahuja VM shows that $\mathrm{T}$ wave amplitude decreased in 35 of 50 patients of POAG (70\%).22 The result of the present study disclosed that the mean Corrected QT interval (QTc) in POAG group $(0.468 \pm 0.0774)$ shortens when compared with control group $(2.362 \pm 0.3283)$. The larger the abstention period the greater the QTc interval, similarly the shorter the R-R interval, the shorter the QTc interval. Through a study Bazett proved that QTc segment duration varies with the heart rate and the corrected QT interval standardizes the QT interval for rate and associated with an imbalance of sympathetic nervous system. ${ }^{20}$ In another study done by Merrdler et al. showed that QTc interval change is assocated with autonomic imbalance. ${ }^{26}$

During evaluation of cardiovascular autonomic function tests in normal subject; Chu-Ts ITJ, Lai JS, Chen WY demonstrated that alteration of QTc associated with autonomic imbalance. ${ }^{27}$ The present study assessed the resting heart rate as parasympathetic activity in POAG cases and in control group. Leon, Shaver and Leonard demonstrated that under normal resting conditions, reduction in vagal activity or its blocking with atropine causes tachycardia whereas blocking of sympathetic activity with propranolol/protalol does not alter heart rate. ${ }^{28}$ They concluded that the parasympathetic nervous system predominates in the heart rate changes. The study done by Kumar R and Ahuja showed that RHR did not establish statistical significance, nevertheless a decreasing trend in mean value is seen, but it is known that RHR is a weak indicator of specific autonomic activity so it may take long time to change. ${ }^{22}$

The present study assessed the parasympathetic activity by using the parameter Valsalva ratio, which shows fall in parasympathetic activity in POAG patients $(1.463 \pm 0.2359)$ when compared with controls $(1.889 \pm 0.4721)$. According to Ewing et al. a Valsalva ratio 1.21 or greater is normal; 1.11 to
1.20 is borderline and 1.10 or is abnormal. ${ }^{19}$ These findings correlate with the Valsalva maneuver test result of the present study to a greater extent. The causative factor is due to Valsalva maneuver being altered by sympathetic and parasympathetic activity equally. Clark and Mapstone using tests based upon cardiovascular reflex responses, could clearly demonstrate the presence of parasympathetic neuropathy in POAG patients. ${ }^{29}$ The present study gives statistically significant difference in standing-to-lying ratio of group POAG $(1.334 \pm 0.1929)$ and group of control $(1.439 \pm 0.2134)$ subjects. Kumar R study showed that SLR was also decreased in 5 of $50(10 \%) .{ }^{22}$ Since SLR is more reliable for long term studies. But result confirmed the idea of parasympathetic dysfunction. These findings are supportive of the results obtained in the present study.

\section{SUMMARY AND CONCLUSION}

The present study shows autonomic involvement in POAG. POAG showed decrease in both sympathetic and parasympathetic activity.

\section{BIBLIOGRAPHY}

1. William LH. Autonomic Insufficiency. Arch Int Med 1982;142:339-44.

2. Dorland's Illustrated Medical Dictionary. 32nd Ed. Saunders: Elsevier; 2011. Autonomic Nervous System; p.1862.

3. Stedman's medical dictionary. 28th ed. Baltimore:Williams \& Wilkins; 2005. Medicine.

4. Rosen field GC, Loose DS, BRS Pharmacology. 4th edition. Philadelphia:Williams \& Wilkins; 2006.

5. Belvisi MG, Stretton CD, Yacoub M, et al. Nitric oxide is the endogenous neurotransmitter of bronchodilator nerves in humans.

Eur J Pharmacol 1992; Jan 14;210(2):221-2.

6. Ehinger B. Adenergic nerves to the eye and to related structures in man and the cynomolgus monkey, Invest opthalmol 1966;5:42.

7. Stone RA, Laties AM, Emson PC. Neuropeptide Y and the ocular innervations of rat guinea pig, cat and monkey. Neuroscience. 1986;17:1207.

8. Ruskell GL. Facial parasympathetic innervations of the choroide blood vessels in monkeys Exp Eye Res 1971;12:166.

9. Stone RA, Kuwayama Y. Substance P- like immune active nerve in the human eye. Arc ophthalmol 1985;103:1207.

10. Alm A Bill. The effect of sympathetic stimulation on blood flow through the uvea, retina and optic nerve in monkey. Invest Ophthalmol. Vis Sci. 1980;19:487.

11. Bryson JM, Wolter JR, O'Keetle NT. Ganglionic cells in the human ciliary body. 1966;75:57.

12. Sears ML, Mosses RA. Adler's physiology of the eye. 7th ed. St. Louis: CV Mosby Co.; 1981.

13. Coleman AL. Glaucoma. Lancet. 1999 Nov 20;354(9192):1803-10.

14. Kanski JJ. Clinical opthalmology. A Systemic Approch. $4^{\text {th }}$ Ed. Oxford: Educational and Professional Publishing Ltd.; 1999.

15. Royal College of Ophthalmology, Glaucoma Annual Evidence update, 2008.

16. National Institute of Health and Clinical Excellence. Glaucoma - clinical guideline. London. NIHCE Press, 2009.

17. Krakau CET, Widakowich J, Wilke K. Measurments of the episcleral venous pressure by means of air jet. Acta Ophthalmol (Copench). 1973;51:185. 
18. Anderson DR. Correlation of the peripapillary anatomy with the disc damage and field abnormalities in glaucoma, Doc Ophthalmol Proc Ser. Sears ML., Mosses RA. Adler's physiology of the eye. 7th ed, St. Lous: CV Mosby; 1981;35:1.

19. Ewing DJ, Campbell IW, Clarke BF. Assessment of cardiovascular effect in diabetic autonomic neuropathy and prognosis implications. ANN Int Med 1980;92:30811.

20. Bazett HC. An analysis of time relationship of the EKG. The Heart $3^{\text {rd }}$ Ed. New York: MC Graw Hill; 1977. 299.

21. Le Blace J. Autonomic nervous system and adaptation to cold in man. J Appl Physiol 1975;39(2):181-186.

22. Kumar R, Ahuja VM. A study of changes in the status of autonomic nervous system in primary open angle glaucoma cases. Indian J Med Sci 1999;53:529-34.

23. Godden JO, Roth GM. The change in the intra-arterial pressure during immersion of hand in cold water. Circulation. 1965;12:963-973.

24. Gherghel D, Orgul, Dubler B. Is vascular regulation in the central artery altered in persons with vasospasm. Arch Ophthalmol. 1999;117:1359-1362.

25. Furedy JJ. A consideration of recent criticism T-wave amplitude under myocardial sympathetic activity. Psychophysiology. 1983;24:204.

26. Merdler A. Beta blockade in asymptomatic diabetic with abnormal rest EKG. Cardiology. 1983;16:1.

27. Chu-Ts ITJ, Lai JS, Chen WY. Evaluation of cardiovascular autonomic function test in normal subjects. Wan 1 Hsueh-Hui-C. 1989;88:404-6.

28. Leon DF, Shaver JA and Leonard JJ. Reflex heart rate control in man. Am Heart J 1970;80:729-39.

29. Clark CV, Mapstone R. Systemic autonomic neuropathy in open angle glaucoma. Doc Ophthalmol 1986;64:179-185.

\begin{tabular}{|c|c|c|c|c|c|}
\hline & \multicolumn{2}{|c|}{ POAG } & \multicolumn{2}{c|}{ Control } & \multirow{2}{*}{ P value } \\
\cline { 2 - 5 } & Mean & S.D & Mean & S.D & \\
\hline Age (Years) & 53.77 & 5.811 & 52.77 & 5.864 & 0.510 \\
\hline \multicolumn{6}{|c|}{ Table: 4.1 (Age-Years) } \\
\hline
\end{tabular}

$\mathrm{P}=$ Nonsignificant

\begin{tabular}{|c|c|c|c|c|c|}
\hline & \multicolumn{2}{|c|}{ POAG } & \multicolumn{2}{c|}{ Control } & P \\
\cline { 2 - 5 } & Mean & S.D & Mean & S.D & \\
\hline Height(Inches) & 63.93 & 3.321 & 65.14 & 3.518 & 0.176 \\
\hline \multicolumn{4}{|c|}{ Table: 4.2 (Height) } \\
\hline
\end{tabular}

$\mathrm{P}=$ Nonsignificant

\begin{tabular}{|c|c|c|c|c|c|}
\hline \multirow{2}{*}{} & \multicolumn{2}{|c|}{ POAG } & \multicolumn{2}{c|}{ Control } & \multirow{2}{*}{ P value } \\
\cline { 2 - 5 } & Mean & S.D & Mean & S.D & \\
\hline $\begin{array}{c}\text { Body } \\
\text { Surface } \\
\text { Area } \\
\left(\mathrm{m}^{2}\right)\end{array}$ & 1.7060 & 0.09216 & 1.7373 & 0.10970 & 0.23600 \\
\hline \multicolumn{5}{|c|}{ Table: 4.3 Body Surface Area ( $\left.\mathbf{m}^{2}\right)$} \\
\hline
\end{tabular}

$\mathrm{P}=$ Nonsignificant

\begin{tabular}{|c|c|c|c|c|c|}
\hline & \multicolumn{2}{|c|}{ POAG } & \multicolumn{2}{|c|}{ Control } & \multirow{2}{*}{$\begin{array}{c}P \\
\text { value }\end{array}$} \\
\hline & Mean & S.D & Mean & S.D & \\
\hline $\begin{array}{l}\text { 'T’ Wave } \\
\text { Amplitude } \\
\text { (mV) }\end{array}$ & 0.161 & 0.1535 & 0.433 & 0.1373 & 0.00 \\
\hline \multicolumn{6}{|c|}{$\begin{array}{c}\text { Table: 4.4 T-Wave Amplitude ( } \mathrm{mV} \text { ) of lead } 11 \text { of EKG of } \\
\text { Control and POAG }\end{array}$} \\
\hline
\end{tabular}

$\mathrm{P}=$ Significant

\begin{tabular}{|c|c|c|c|c|c|}
\hline & \multicolumn{2}{|c|}{ POAG } & \multicolumn{2}{c|}{ Control } & P \\
\cline { 2 - 5 } & Mean & S.D & Mean & S.D & value \\
\hline $\begin{array}{c}\text { Systolic CPR } \\
\text { (mmHg) }\end{array}$ & 17.27 & 3.463 & 37.13 & 7.195 & 0.000 \\
\hline \multicolumn{4}{|c|}{ Table: 4.5 Systolic CPR (mmHg) } \\
\hline
\end{tabular}

$\mathrm{P}=$ Significant

\begin{tabular}{|c|c|c|c|c|c|}
\hline & \multicolumn{2}{|c|}{ POAG } & \multicolumn{2}{c|}{ Control } & P \\
\cline { 2 - 5 } & Mean & S.D & Mean & S.D & value \\
\hline $\begin{array}{c}\text { Diastolic } \\
\text { CPR (mmHg) }\end{array}$ & 14.27 & 4.258 & 22.57 & 5.157 & 0.000 \\
\hline \multicolumn{6}{|c|}{ Table: 4.6 Diastolic CPR (mmHg) } \\
\hline
\end{tabular}

$\mathrm{P}=$ Significant

\begin{tabular}{|c|c|c|c|c|c|}
\hline \multirow{2}{*}{} & \multicolumn{2}{|c|}{ POAG } & \multicolumn{2}{c|}{ Control } & \multirow{2}{*}{ v } \\
\cline { 2 - 5 } & Mean & S.D & Mean & S.D & value \\
\hline $\begin{array}{c}\text { Corrected } \\
\text { QT } \\
\begin{array}{c}\text { Interva } \\
\text { l(sec) }\end{array}\end{array}$ & 0.468 & 0.0774 & 2.362 & 0.3283 & 0.00 \\
\hline \multicolumn{3}{|c|}{ Table: 4.7 Corrected QT Interval (sec) } \\
\hline
\end{tabular}

$\mathrm{P}=$ Significant

\begin{tabular}{|c|c|c|c|c|c|}
\hline & \multicolumn{2}{|c|}{ POAG } & \multicolumn{2}{c|}{ Control } & \multirow{2}{*}{$\begin{array}{c}\text { v } \\
\text { value }\end{array}$} \\
\cline { 2 - 5 } & Mean & S.D & Mean & S.D & \\
\hline $\begin{array}{c}\text { Resting } \\
\text { Heart Rate } \\
\text { (Beats/min) }\end{array}$ & 64.88 & 4.048 & 69.22 & 14.024 & 0.112 \\
\hline \multicolumn{1}{|c|}{ Table: 4.8 Resting Heart Rate (Beats/min) } \\
\hline
\end{tabular}

$\mathrm{P}=$ Nonsignificant

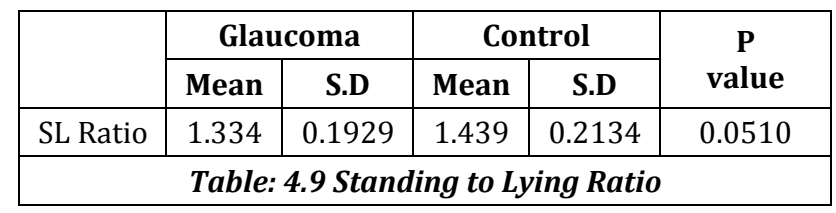

$\mathrm{P}=$ Significant

\begin{tabular}{|c|c|c|c|c|c|}
\hline & \multicolumn{2}{|c|}{ POAG } & \multicolumn{2}{c|}{ Control } & P \\
& Mean & S.D & Mean & S.D & value \\
\hline $\begin{array}{c}\text { Valasalva } \\
\text { Ratio }\end{array}$ & 1.463 & 0.2359 & 1.889 & 0.4721 & 0.0001 \\
\hline \multicolumn{4}{|c|}{ Table: 4.10 Valsalva Ratio } \\
\hline
\end{tabular}

$\mathrm{P}=$ Significant

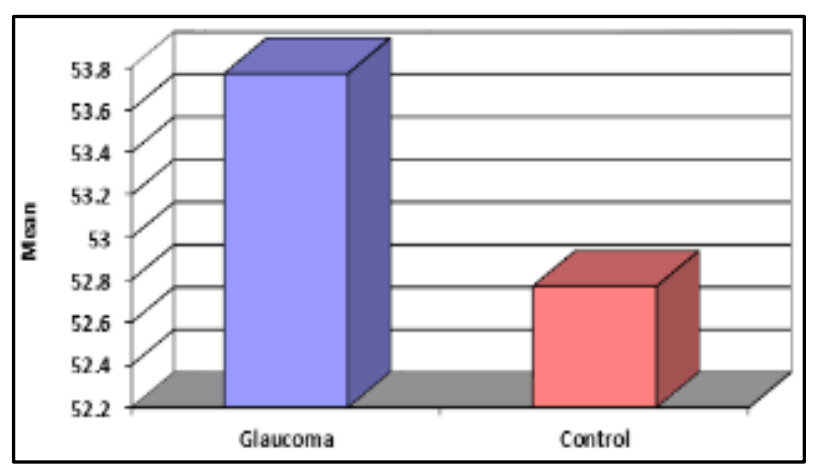

Fig. 1: Chart showing mean value of age of POAG and Control 


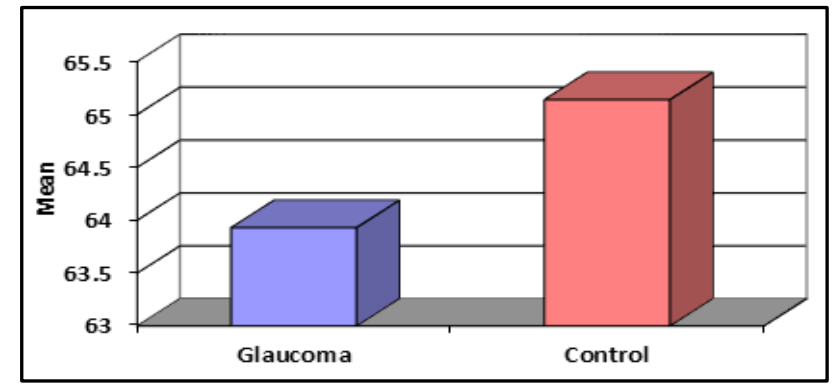

Fig. 2: Chart showing mean value of Height of POAG and Control

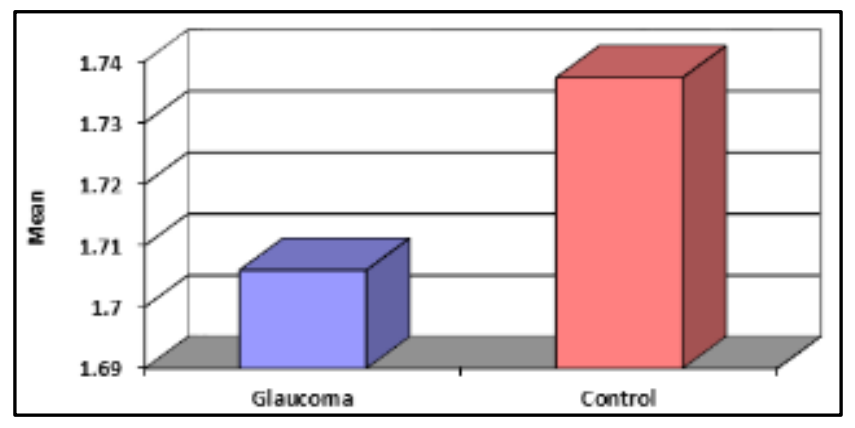

Fig. 3: Chart showing mean value of Body Surface Area of POAG and Control

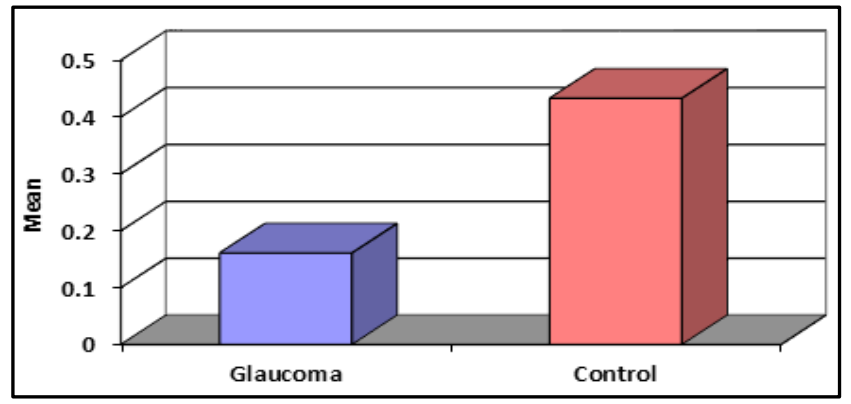

Fig. 4: Chart showing mean value of T-wave amplitude of lead11 of EKG of two group POAG and Control

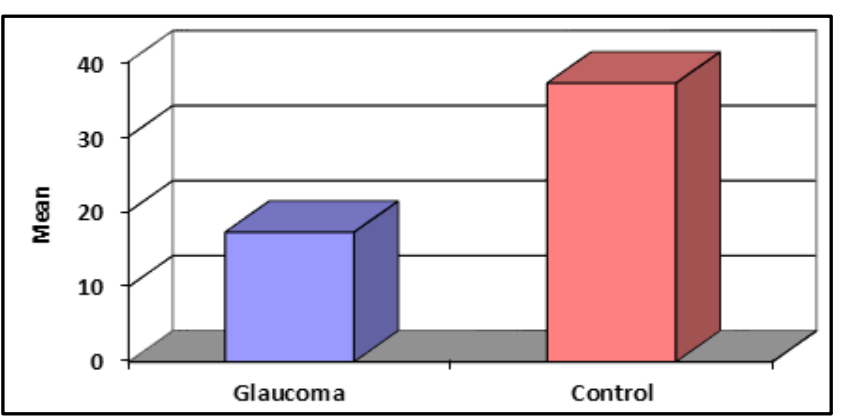

Fig. 5: Chart showing mean value of systolic CPR of Control and POAG

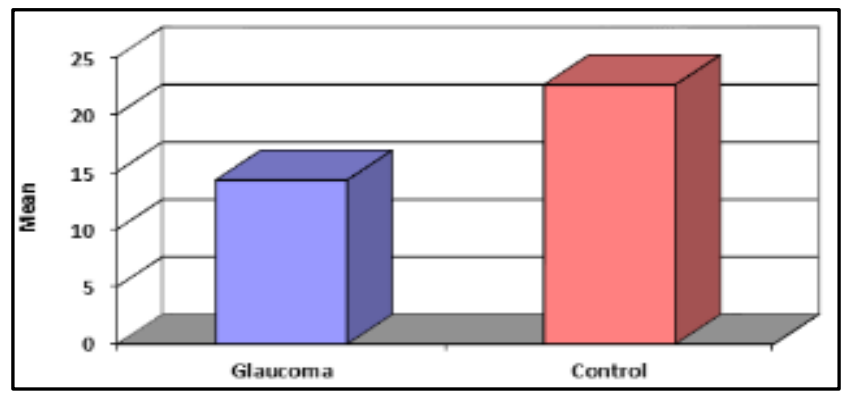

Fig. 6: Chart showing mean value of diastolic CPR of POAG and Control

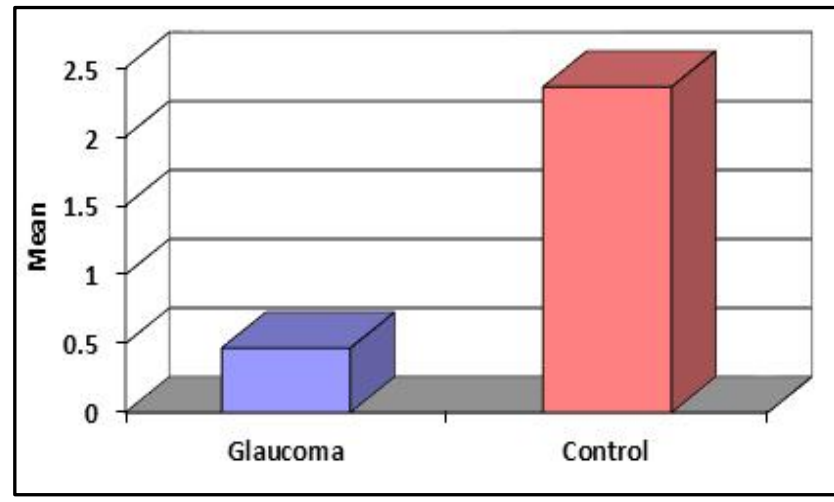

Fig. 7: Chart showing mean value of Corrected $Q T$ interval of Control and POAG

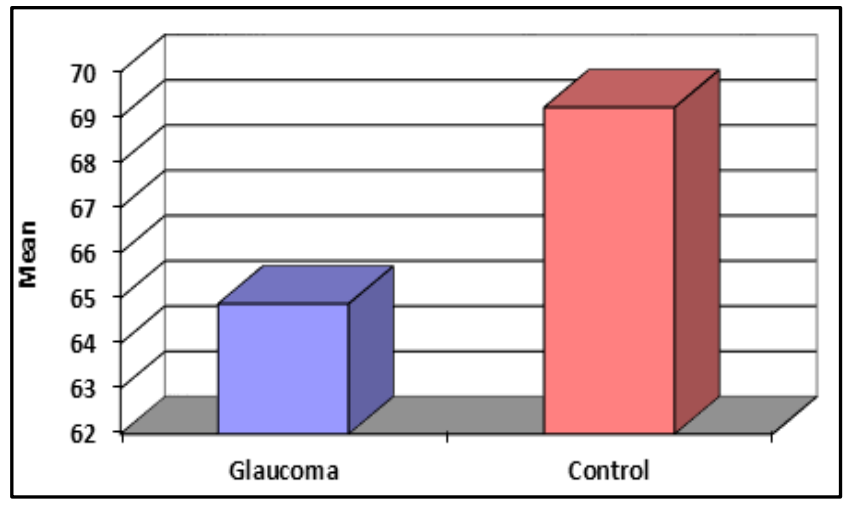

Fig. 8: Chart showing mean value of HR (Beats/min) in Control and POAG

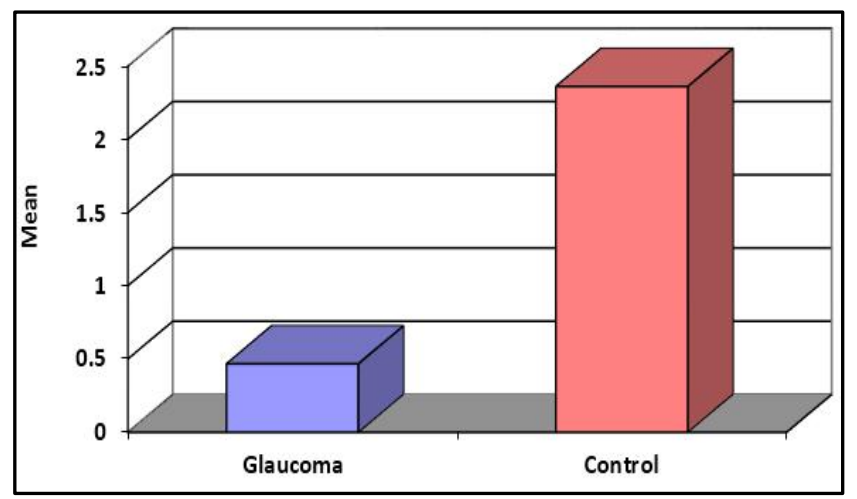

Fig.9:- Chart showing mean value of HR (Beats/min)in control and POAG.

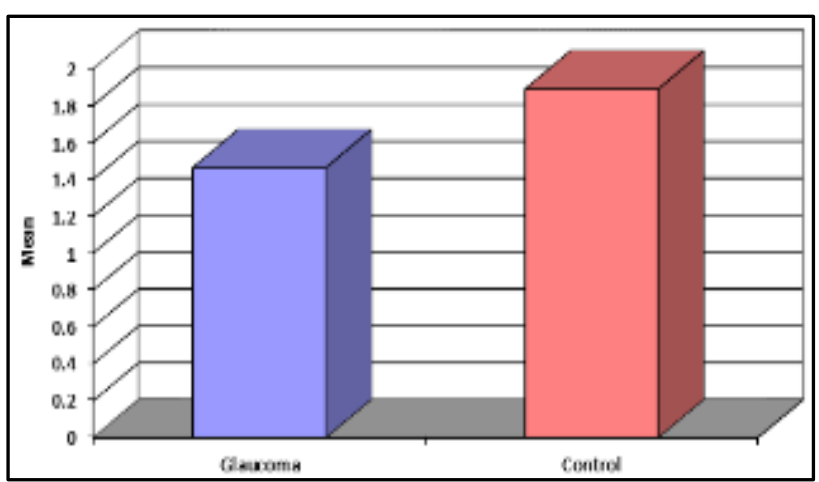

Fig. 10: Chart showing mean value of Valsalva ratio of Control and POAG group 